\title{
The dopamine and cannabinoid interaction in the modulation of emotions and cognition: assessing the role of cannabinoid CB1 receptor in neurons expressing dopamine D1 receptors
}

\author{
Ana Luisa Terzian ${ }^{1,2}$, Filippo Drago ${ }^{3}$, Carsten T. Wotjak ${ }^{1}$ and Vincenzo Micale ${ }^{1,3 *}$ \\ Research Group "Neuronal Plasticity," Max Planck Institute of Psychiatry, Munich, Germany \\ 2 Graduate School of Systemic Neuroscience, Ludwig Maximilians Universität, Munich, Germany \\ ${ }^{3}$ Department of Clinical and Molecular Biomedicine, Section of Pharmacology and Biochemistry, University of Catania, Catania, Italy
}

\section{Edited by:}

Patrizia Campolongo, Università degli Studi di Roma La Sapienza, Italy

\section{Reviewed by:}

Irit Akirav, University of Haifa, Israel Liana Fattore, University of Cagliari, Italy

\section{*Correspondence:}

Vincenzo Micale, Research Group "Neuronal Plasticity," Max-PlanckInstitut für Psychiatrie, Kraepelinstrasse 2-10, München D-80804, Germany. e-mail: vincenzomicale@inwind.it
Although cannabinoid CB1 receptors (CB1Rs) are densely expressed in neurons expressing dopamine $\mathrm{D} 1$ receptors (D1Rs), it is not fully understood to what extent they modulate emotional behaviors. We used conditional CB1R knock-out animals lacking CB1Rs in neurons expressing $\mathrm{D} 1 \mathrm{R}\left(\mathrm{D} 1-\mathrm{CB} 1^{-1}\right)$ in order to answer this question. To elucidate the behavioral effects of CB1R deficiency in this specific neuronal subpopulation, we subjected $\mathrm{D} 1-\mathrm{CB} 1^{-1-}$ mice to a battery of behavioral tests which included exploration-based tests, depressive-like behavioral tests, social behavior, and fear-related memory paradigms. D1-CB1-- did not show any difference in the exploration-based paradigms such as open field, elevated plus maze, or novel object investigation test, except for an increase in novelty-induced grooming. By contrast, they showed a mild anhedonia-like state as described by the slightly decreased preference for sweet solution, as compared to wild-type control group. This decrease, however, could be observed only during the first day of exposure, thus suggesting increased neophobia as an alternative explanation. Accordingly, mutant mice performed normally in the forced swim test, a procedure widely used for evaluating behavioral despair in rodents. However, weak- to moderate anxiety-like phenotypes were evident when D1-CB1-- mice were tested for social behavior. Most strikingly, D1-CB1-/ mice exhibited significantly increased contextual and auditory-cued fear, with attenuated within session extinction, suggesting that a specific reduction of endocannabinoid signaling in neurons expressing dopamine D1Rs is able to affect acute fear adaptation. These results provided first direct evidence for a cross-talk between dopaminergic D1Rs and endocannabinoid system in terms of controlling negative affect.

Keywords: cannabinoids, CB1R, dopamine, D1R, social behavior, aversive memories, anxiety, fear extinction

\section{INTRODUCTION}

In the central nervous system (CNS), endogenous cannabinoids compounds activate cannabinoid CB1 receptors (CB1Rs), which are located pre-synaptically in several brain regions such as prefrontal cortex, hippocampus, amygdala, and basal ganglia. They act as inhibitory retrograde signaling messengers at glutamatergic and GABAergic synapses, modulating the release of several neurotransmitters such as acetylcholine or dopamine (DA) (Marsicano and Lutz, 1999; Piomelli, 2003). Thus, the endocannabinoid system (ECS), through its neuromodulating activity, could be involved in several physiological functions as memory processing, pain perception, locomotion, and inflammation; additionally, its dysregulation could underlie several pathological conditions known to accompanying psychiatric disorders (Di Marzo, 2008).

The role of the dopaminergic (DAergic) neurotransmitter system in the processing of emotional behavior is well established and supported by several preclinical and clinical data showing that DA, acting on D1- or D2-like receptors, is one of the most important neuromodulators of fear and anxiety (LeDoux, 2000). A DAergic and EC interaction at different anatomical levels (i.e., amygdala, nucleus accumbens and striatum) seems to be involved in several neurophysiological responses. More specifically, it has been suggested that CB1R signaling modulates DAergic pathways by influencing directly or indirectly the activity of DAergic neurons through either post- or pre-synaptic mechanisms (Laviolette and Grace, 2006). However, both the mechanisms through which DAergic and EC signaling cross-talk and the role played by the dopamine D1 receptor positive neurons still remain unclear. The dopamine D1 receptors (D1Rs), which belong to the "D1-like" group, are expressed in brain regions involved in aversive learning and memory such as nucleus accumbens, hippocampus, and amygdala. (Kamei et al., 1995; Bernabeu et al., 1997; El-Ghundi et al., 2001; Nagai et al., 2007). Interestingly, the colocalization of CB1Rs with D1Rs indicates that these receptors may interact by potentially modifying their respective functions with important behavioral and pharmacological consequences (Hermann et al., 2002).

Although the use of complete CB1 knock-out mice together with pharmacological approaches suggest that ECS controls fear and anxiety primarily under highly aversive situations (Moreira and Wotjak, 2010), the cellular substrates of these effects with regard to specific neuronal subpopulation involved (i.e., dopamine receptor D1-expressing neurons) is still largely unexplored, except 
for a specific contribution of principal neurons of the forebrain (Kamprath et al., 2009). Thus, conditional CB1 knock-out animals, lacking CB1Rs specifically in D1R positive neurons provide an important tool to answer these questions.

Based on the above premises, this study was undertaken to investigate the role of CB1R signaling in the dopamine receptor D1-expressing neurons in affecting emotional behavior. For this purpose, conditional CB1 mutant mice, lacking CB1Rs expression in neurons containing dopamine D1Rs (D1-CB1 ${ }^{-1-}$; Monory et al., 2007), were submitted to a battery of behavioral tests, which included exploration-based tests, depressive-like behavioral tests, and fear-related memory paradigms. Since it has been hypothesized that ECS is a relevant modulator of dopamine D1Rs-mediated behaviors including social activity (Martín et al., 2008; Zenko et al., 2011), we also evaluated the phenotype of these mice in social approach tests.

\section{MATERIALS AND METHODS ANIMALS}

Male mice at the age of $8-16$ weeks were used throughout the experiments. Conditional D1-CB1 knock-out mice (D1-CB1 ${ }^{-1-}$ or $\mathrm{KO}$ ) and their respective wild-type (WT) littermate controls $\left(\mathrm{D} 1-\mathrm{CB}^{+/+}\right.$or $\left.\mathrm{WT}\right)$ were generated and genotyped as previously described (Monory et al., 2007). Animals ( $n=6-10$ per group) were single housed and maintained in standard conditions with food and water ad libitum under a 12-h inverse light-dark (LD) cycle (lights off at 9 a.m.) for at least 14 days before starting the experiments. All behavioral experiments were performed during the active (dark) phase of mice between 9:30 a.m. and 5 p.m. Experimenters were always blind to the genotype. All behavioral tests took place in an experimental room with the same LD cycle and environmental conditions (i.e., humidity, temperature) as in the housing facility. All experiments were carried out according to the European Community Council Directive 86/609/EEC and efforts have been made to minimize animal suffering and reduce the number of animals used.

\section{BEHAVIORAL TESTING \\ Novelty-induced grooming test}

Grooming behavior was observed under the same environmental conditions as previously described (Kalueff and Tuohimaa, 2005). The mice were placed individually into a clean unfamiliar Plexiglass box $(27 \mathrm{~cm} \times 16 \mathrm{~cm} \times 12 \mathrm{~cm})$ without bedding for $10 \mathrm{~min}$. Three ethological measures of grooming activity were scored: latency to start grooming, grooming episodes (washing, general grooming, scratching, licking of paws, or genital grooming), and total time spent grooming. All trials were recorded for subsequent video analysis.

\section{Open field test}

Exploratory activity of $\mathrm{D} 1-\mathrm{CB}^{-1-}$ and WT mice was evaluated in the open field (OF) test, as previously described (Jacob et al., 2009). The experiment was performed in a squared box $(26 \mathrm{~cm} \times 26 \mathrm{~cm})$, in which the animal was placed in the central zone of the apparatus equipped with infrared beams (TruScan; Coulbourn Instruments, Allentown, PA, USA) and allowed to explore for $30 \mathrm{~min}$ at 300 lux. All sensor rings were connected via interface to a computer equipped with TruScan Software Version 99 (Coulbourn Instruments). Boxes and sensor rings were surrounded by an additional box made of opaque Plexiglas side walls $(47 \mathrm{~cm} \times 47 \mathrm{~cm} \times 38 \mathrm{~cm})$ without roof and floor. Horizontal locomotion (total, margin, or central distance moved) vertical movements (exploratory rearing) and time spent at rest were analyzed during the 30 -min monitoring period with a sampling rate of $4 \mathrm{~Hz}$. After each session, the apparatus was cleaned with a solution containing neutral soap.

\section{Elevated plus maze test}

The apparatus consisted of two opposite open arms, $(30 \mathrm{~cm} \times 5 \mathrm{~cm})$ and two arms with walls $(30 \mathrm{~cm} \times 5 \mathrm{~cm} \times 14 \mathrm{~cm})$ that were attached to a central platform $(5 \mathrm{~cm} \times 5 \mathrm{~cm})$ to form a cross. The maze was elevated $50 \mathrm{~cm}$ from the floor (Pellow et al., 1985). Illumination measured at the center of the maze was 300 lux. The animal was placed in the center of the maze facing one of the closed arms, and observed for $5 \mathrm{~min}$, according to the following parameters: number of entries in the open or closed arms and time of permanence in each arm (i.e., the time spent by the animal in the open or closed arms). An entry was defined as all four paws having crossed the line between an arm and the central area. It is accepted that the anxiolytic effect of a drug treatment is illustrated by increased parameters in open arms (time and/or number of entries; Pamplona et al., 2011: for pharmacological validation of our current set-up). The augmented percentage of entries in open arms over the total entries in both arms is a good indicator of reduced anxious-like phenotype as well. Entries in closed arms and total entries reflect the motor component of the exploratory activity. On removal of each mouse, the maze floor was carefully wiped with a wet towel. All trials were recorded on a HDD using a video-camera and then scored off-line by an experienced observer by means of a video/computer system ANY-MAZE (Stoelting).

\section{Light/dark test}

Set-up and test procedure were essentially the same as previously described (Jacob et al., 2009). The LD box was divided in two compartments: (1) one dark compartment $(15 \mathrm{~cm} \times 20 \mathrm{~cm} \times 38 \mathrm{~cm})$ with black walls and (2) one lit compartment $(30 \mathrm{~cm} \times 20 \mathrm{~cm} \times 38 \mathrm{~cm})$ with white plastic walls. Both compartments were connected by a 4-cm long tunnel. Light intensity was 600 lux in the light compartment and 15 lux in the dark compartment measured at floor level. Mice were placed into the corner of the dark compartment at the start of the experiment which lasted for $5 \mathrm{~min}$. After each test, the LD box was thoroughly cleaned with soap and water. Entries and time spent in the light compartment were assessed by video analysis by a trained observer. These two variables were expressed as percentage of the total observation period and the total number of LD transitions, respectively.

\section{Novel object investigation test}

The novel object investigation (NOI) test was performed at 30 lux (which still allowed the assessment of exploration of the objects) for $10 \mathrm{~min}$. Experimental subjects were habituated to the test arena $(36 \mathrm{~cm} \times 22 \mathrm{~cm} \times 14 \mathrm{~cm}$, with sawdust bedding material and transparent walls) for 2 days for $10 \mathrm{~min}$ (one cage per mouse without cleaning or changing of bedding). On the third day, mice were transferred into the same test cages and two identical objects (cone 
made of aluminum: $\varnothing 6 \mathrm{~cm}+\mathrm{H} 13 \mathrm{~cm}$ ) were placed in a symmetrical position at the short walls of the cages. Between animals, objects were thoroughly cleaned with water containing detergent to eliminate olfactory cues. Objects were heavy enough that a mouse could not displace them. Every trial was video recorded and analyzed using ANY-MAZE (Stoelting). Investigation was defined as follows: directing the nose toward the object at a distance of not more than $2 \mathrm{~cm}$ and/or touching the object with the nose and paws (Jacob et al., 2009).

\section{Sucrose consumption test}

During this test, mice are given a free choice between two bottles for $10 \mathrm{~h}$-one filled with $2.5 \%$ sucrose solution and the other with tap water - for two consecutive days (Strekalova and Steinbusch, 2010). To prevent possible effects of side preference in drinking behavior, the bottles position was switched in the mid-point of testing. Animals were not food or water-deprived before the test. For habituation, 1 day prior to the first testing day, animals were allowed to drink a $2.5 \%$ sucrose solution for $2 \mathrm{~h}$. The consumption in water, sucrose solution, and total intake of liquids were estimated simultaneously in the both groups by weighing the bottles before and after each trial. The preference for sucrose was calculated as a percentage of the consumed sucrose solution from the total amount of liquid drunk, by the formula: Sucrose Preference $=V$ (Sucrose solution $) /[\mathrm{V}($ Sucrose solution $)+\mathrm{V}$ (Water $)] \times 100 \%$.

\section{Forced swim test}

The forced swim test (FST) employed here was essentially similar to that described elsewhere (Porsolt et al., 1978). Mice were individually placed into transparent cylinders (height $23.5 \mathrm{~cm}$; diameter $16.5 \mathrm{~cm}$ ) containing $15 \mathrm{~cm}$ water at $25 \pm 1^{\circ} \mathrm{C}$ for $6 \mathrm{~min}$. The water was changed after each trial. After vigorous activity, swimming attempts cease and the animal adopts a characteristic immobile posture. A mouse is judged to be immobile when it floats in upright position and makes only small movements to keep its head above water. The duration of mobility was recorded during the last 4-min of the 6-min testing period. All trials were recorded for subsequent off-line analysis.

\section{Social interaction test}

The procedure was adopted from (Smit-Rigter et al., 2010). Experiments were performed in a new cage $(27 \mathrm{~cm} \times 16 \mathrm{~cm} \times 12 \mathrm{~cm})$ with fresh bedding at 5 lux (i.e., red light) or 700 lux (light intensity measured at the level of test cages). The lid of the new cage was removed and the walls elongated by $12.5 \mathrm{~cm}$ of semi transparent plastic. Briefly, pairs of unfamiliar mice of the same genotype $(n=7$ pairs of $\mathrm{D} 1-\mathrm{CB1}^{-1-}$ and WT) were placed into the cage for $5 \mathrm{~min}$. The time spent in social interactions (SI; active contact such as sniffing, licking, close following, and grooming) was recorded for each pair of mice. Each session was video recorded and analyzed off-line using ANY-MAZE (Stoelting).

\section{Social investigation test}

Social investigation (SInv) task was conducted as previously described with slight modifications (Crawley et al., 2007). It took place in a rectangular box made of white PVC walls and with a dark gray PVC floor. The box was divided into three equal compartments $(30 \mathrm{~cm} \times 30 \mathrm{~cm} \times 30 \mathrm{~cm})$ that were interconnected by small opening $(6 \mathrm{~cm} \times 5 \mathrm{~cm})$ with guillotine doors. Each animal was allowed to free exploration of the apparatus for $10 \mathrm{~min}$ (habituation). An empty perforated $50 \mathrm{ml}$ falcon tube was placed in each side of the box. This $10 \mathrm{~min}$ exposure was designed to familiarize the subject mouse with the testing environment. After habituation session, the animal was kept in the center compartment and one of the tubes was replaced by a tube containing an ovariectomized female. For the next 10 min session, the mouse was allowed to explore all three compartments and the time spent in the SInv (active contact such as sniffing) was recorded.

\section{Fear conditioning task}

The set-up has been described and displayed in detail before (Kamprath and Wotjak, 2004; Plendl and Wotjak, 2010). Two different protocols were programmed and carried out. The first experiment was performed in two contexts: (1) the neutral test context - a cylinder made of transparent Plexiglas, lined with wood shavings - and (2) the shock context - a cubic-shaped box with a metal grid for shock application. For conditioning $(\mathrm{d} 0)$, mice were placed in the conditioning context. Three minutes later, a tone $(80 \mathrm{~dB}$, $9 \mathrm{kHz}$ sine-wave, $10 \mathrm{~ms}$ rising, and falling time) was presented to the animals for $20 \mathrm{~s}$ that coterminated with a 2 -s scrambled electric footshock of $0.7 \mathrm{~mA}$. Mice were returned to their home cages 60 s later. On day 1 ( $d 1)$, mice were exposed to the neutral context and on day 2 ( $\mathrm{d} 2$ ) to the grid context for 7 and $3 \mathrm{~min}$, respectively. Briefly, mice were placed in the test context, which differed from the conditioning context in material, shape, surface texture, and odor of the cleaning solution. After an initial 3 min of habituation, a 180 -s permanent tone [ $9 \mathrm{kHz}, 80 \mathrm{~dB}$, sine-wave] was delivered. To test the contextual freezing, animals were re-exposed to the shock chamber for 3 min without tone presentation and without further shock application, and immediately returned to their home cages afterward.

In the second experiment, mice were conditioned as described for the first experiment. On day 1 (d1) and on day 7 (d7), mice were exposed to the 180 -s tone in the neutral test context. Animals' behavior was video recorded by small CCD cameras (Conrad Electronics, Hirschau, Germany) and rated off-line by a trained observer (EVENTLOG, designed by Robert Henderson, 1986). Freezing behavior was defined as immobility except for respiration movements.

\section{EXPERIMENTAL DESIGN}

Behavioral experiments were conducted in two screens to reduce the number of animals used for the study with separate cohorts of animals for every screen (Table 1). If not stated otherwise, the different screens were accomplished with 4-5 days in between two consecutive tests. Animals were submitted to a battery of behavioral tests, which was divided in three main categories, in the following order: (1) low- or mild-stress situation (a) exploratory-based approach avoidance conflict tests: open field, elevated plus maze, light/dark, novel object investigation, and noveltyinduced grooming (b) depressive-like behavior paradigms: sucrose consumption and forced swim test (2) social approach: social interaction and social investigation test (3) high-stress situation: fear conditioning (FC) tests. The order of tests within the battery was designed in such manner that mice would be evaluated on what were thought to be least invasive tests before 
Table 1 | Comprehensive behavioral test battery of D1-CB1 knockout mice.

\begin{tabular}{lllll}
\hline Test & Age (weeks) & Days & $\boldsymbol{n}$ & Results \\
\hline \multicolumn{2}{l}{ FIRST GROUP } & & & \\
OF & $8-10$ & 1 & $6-9$ & Figures 1A-F \\
EPM & $8-10$ & 5 & $7-8$ & Figures 2A, B \\
LD & $9-11$ & 9 & $8-9$ & Figures 2C,D \\
SI & $9-11$ & 13 & $6-8$ & Figures 6A,B \\
FST & $10-12$ & 20 & $7-9$ & Figure 5B \\
FC & $11-13$ & 27 & $8-9$ & Figures 7A,B \\
SECOND GROUP & & & \\
NGT & $8-10$ & 2 & $8-9$ & Figures 4A-C \\
NOI & $8-10$ & 1 & $8-10$ & Figure 3 \\
SC & $8-10$ & 5 & 10 & Figure 5A \\
SInv & $9-11$ & 9 & $9-10$ & Figures 6C,D \\
FC & $11-13$ & 27 & $9-10$ & Figures 7C,D \\
\hline
\end{tabular}

n, Animal number; OF, open field; EPM, elevated plus maze; LD, light/dark; SI, social interaction; FST, forced swim test; FC, fear conditioning; NOI, novel object investigation; SC, sucrose consumption; SInv, social investigation; NGT, noveltyinduced grooming test.

being tested on more invasive assays. This design was developed with the assumptions that testing from least to most invasive would allow for recovery time between tests and would reduce the likelihood that behavioral responses would be influenced by previous testing experience.

\section{STATISTICAL ANALYSIS}

Data were analyzed using unpaired $t$-test or two-factor ANOVA by means of Sigma Stat 3.5 (Systat Software Inc., San Jose, CA, USA). Newman-Keuls test was used as post hoc test, if appropriate. Data are presented as mean \pm SEM. Statistical significance was accepted if $p<0.05$.

\section{RESULTS \\ EXPLORATORY AVOIDANCE CONFLICT TESTS \\ Open field test}

In the OF test, there was no difference in the exploratory activity between D1-CB1 ${ }^{--}$and WT mice (Figures $\mathbf{1 A - F}$ ). Both groups showed the same horizontal activity (total distance: $t=1.246$; $p=0.2348$; central distance: $t=1.501 ; p=0.1574$, margin distance: $t=0.2401 ; p=0.8140)$, total duration of movement $(t=1.217$; $p=0.2452)$, rearing $(t=1.715 ; p=0.1101)$, and jumping episodes $(t=1.344 ; p=0.2021)$. This response indicates that in our test conditions, genetic deletion of CB1 in neurons expressing D1Rs did not alter basal locomotor activity of mice.

\section{Elevated plus maze and light/dark test}

As described in Figures 2A-D, statistical analysis did not reveal any significant difference between $\mathrm{D} 1-\mathrm{CB}^{-/-}$and WT mice both in the time spent $(t=0.5568 ; \mathrm{df}=14 ; p=0.5871)$ or in the number of entries ( $t=0.6133$; df $=14 ; p=0.5502)$ into open arms of the EPM test. Also, there was no difference in the time spent $(t=0.2827$; $\mathrm{df}=15 ; p=0.7813)$ or in number of entries $(t=0.9739$; $\mathrm{df}=15$; $p=0.3430$ ) into light compartment of the LD test. No locomotion

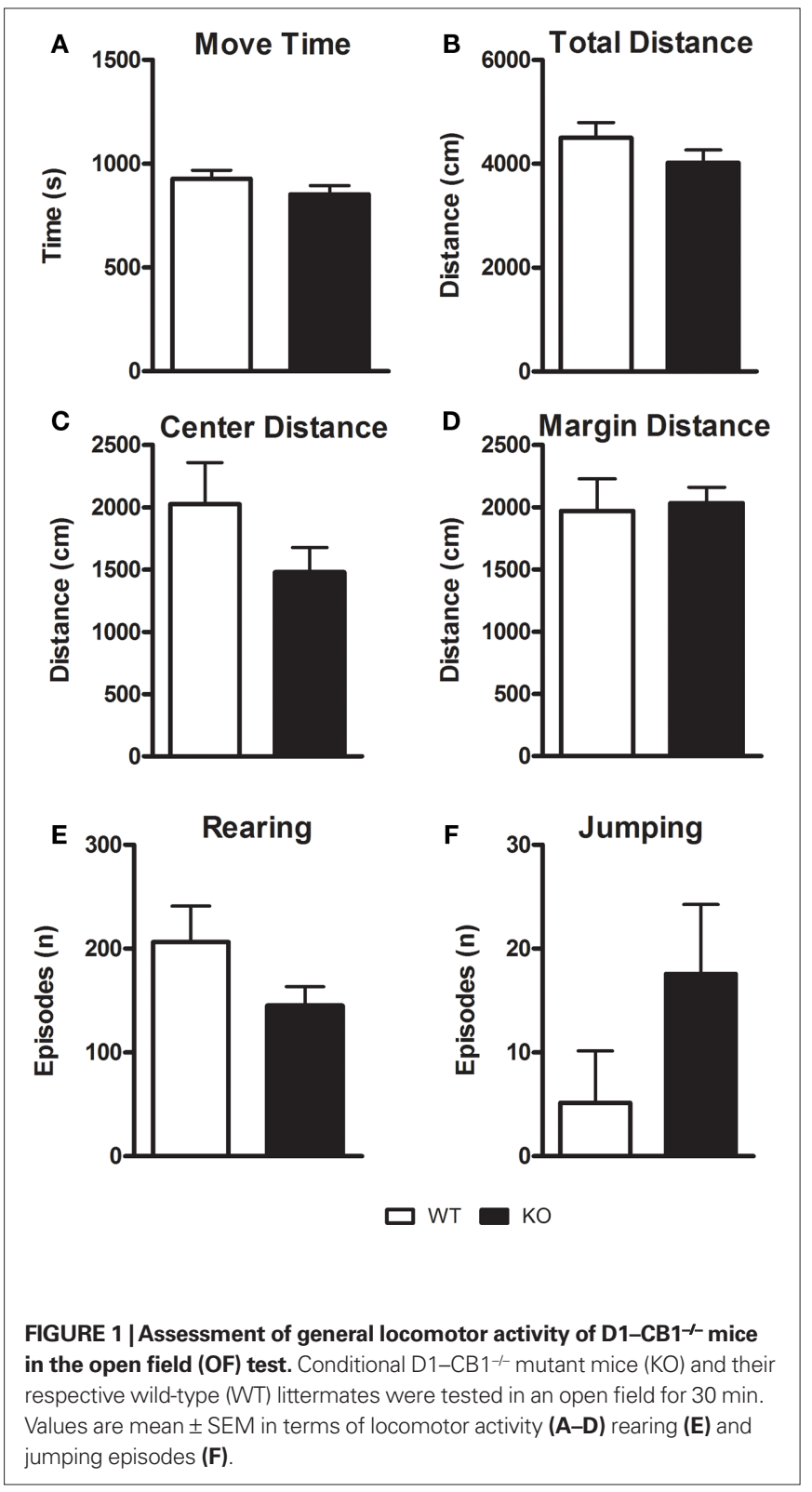

difference was found, considering the total arm entries $(t=0.7276$; $\mathrm{df}=14 ; p=0.4798)$ and the total $\mathrm{LD}$ transitions $(t=0.8154 ; \mathrm{df}=15$; $p=0.4255)$ as index.

\section{Novel object investigation}

Unpaired $t$-test showed that $\mathrm{D} 1-\mathrm{CB}^{-1-}$ and WT mice, during the 10 -min test, spent the same amount of time investigating the pair of novel objects $(t=0.5887 ; p=0.5643)$, as well as they approached them with the same frequency $(t=0.5705 ; p=0.5762$; Figure 3$)$.

\section{Novelty-induced grooming activity test}

As described in Figures $4 \mathrm{~A}-\mathrm{C}, \mathrm{D} 1-\mathrm{CB}^{-/-}$mice performed more grooming episodes $(t=2.240 ; p<0.05 ; \mathrm{df}=15)$ as well as they spent more time grooming as compared to WT animals $(t=2.568 ; p<0.05$; $\mathrm{df}=15)$. However, the latency to start grooming was not significantly different between the two groups $(t=1.170 ; p=0.2603 ; \mathrm{df}=15)$. 


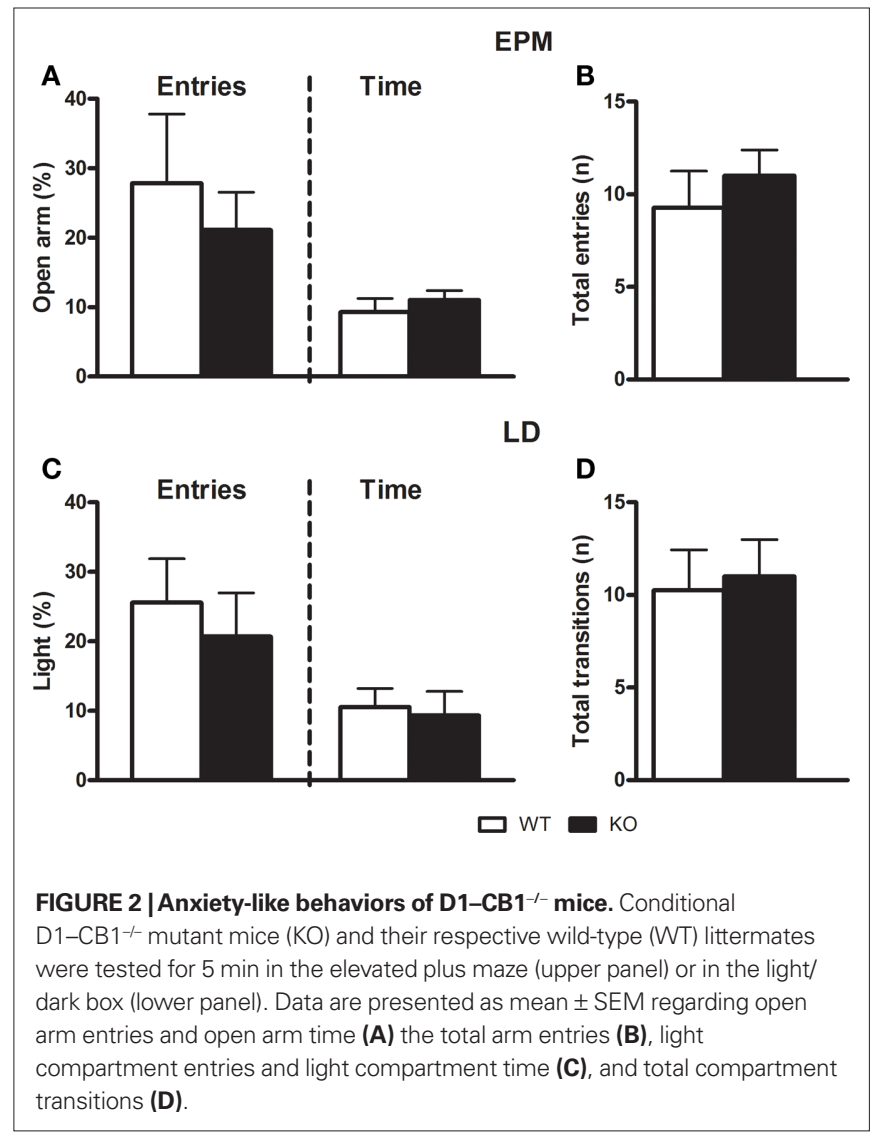

\section{DEPRESSIVE-LIKE BEHAVIOR}

\section{Forced swim test and sucrose consumption}

As described in Figure 5, D1-CB1 $1^{-/-}$mice showed a significant lower SC as compared to WT mice on the first $(t=2.868 ; p<0.05)$, but not on the second testing day $(t=0.3575 ; p=0.7249)$. However, WT and D1-CB1 ${ }^{-1-}$ mice showed a high percentage of SC as compared to the total amount of liquid consumed. In the FST, although D1-CB1 ${ }^{-/-}$mice showed a decrease in the mobility as compared to WT animals, the difference between the two genotypes did not reach statistical significance $(t=1.904$; $p=0.0777)$.

\section{SOCIAL ACTIVITY TESTS \\ Social interaction}

As described in Figures 6A,B, two-way ANOVA (factor 1: light intensity, factor 2: genotype) revealed a main effect of light intensity $\left(F_{1,13}=14.656 ; p<0.01\right)$ genotype $\left(F_{1,13}=6.366 ; p<0.05\right)$ and $\mathrm{a}$ light intensity $\times$ genotype interaction $\left(F_{1,13}=10.904 ; p<0.01\right)$ for time of interaction. There were also a main effect of light intensity $\left(F_{1,13}=18.472 ; p<0.01\right)$ genotype $\left(F_{1,13}=5.285 ; p<0.05\right)$ and $\mathrm{a}$ light intensity $\times$ genotype interaction $\left(F_{1,13}=12.947 ; p<0.01\right)$ for the frequency of interaction. Post hoc analysis showed that in the less aversive environment ( $0 \mathrm{lux}$ ), $\mathrm{D} 1-\mathrm{CB}^{-/-}$expressed a lower SI during the 5-min test than WT mice as described by the decreased number and time of interactions $(p<0.05)$. WT approached the low level of performance seen in $\mathrm{D} 1-\mathrm{CB}^{-/-}$under aversive conditions (700 lux).
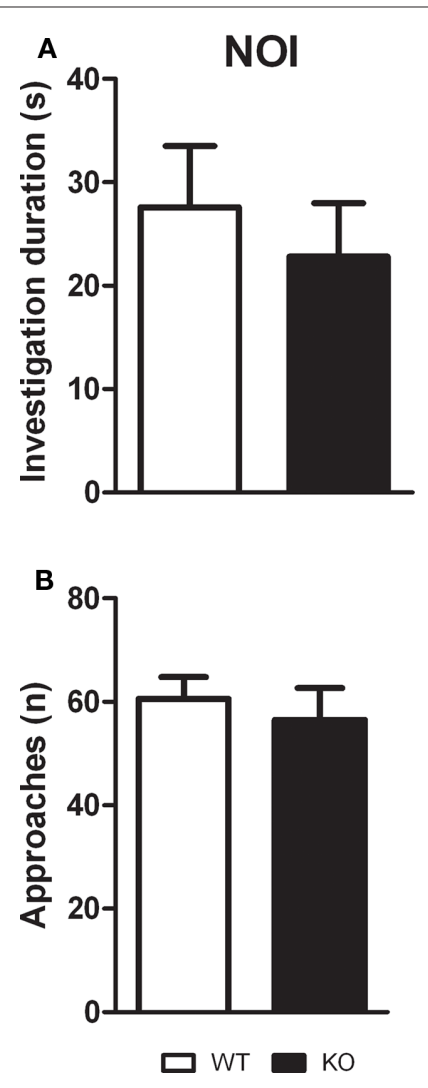

FIGURE 3 | Novel object investigation test. Conditional D1-CB1 $1^{-/-}$mutant mice (KO) and their respective wild-type (WT) littermates were exposed to two novel objects for $10 \mathrm{~min}$. Data are presented as mean \pm SEM regarding total investigation duration (A) and number of approaches (B).

\section{Social investigation}

Figures 6C,D describe the time and the number of active approaches toward the empty falcon tube vs. the tube containing the ovariectomized female. Two-way ANOVA analyses (factor 1: object, factor 2: genotype) revealed a main effect of object (number of interaction: $F_{1,34}=35.588 ; p<0.001$; time of interaction: $F_{1,34}=25.023$; $p<0.001$ ), but no main effect of genotype (number of interaction: $F_{1,34}=0.0182 ; p=0.893$; time of interaction: $F_{1,34}=1.402$; $p=0.245$ ) or a object $\times$ genotype interaction (number of interaction: $F_{1,34}=0.839 ; p=0.366$; time of interaction: $F_{1,34}=1.780$; $p=0.191)$, indicating that mice of both genotype display a preference for the ovariectomized female. Additional $t$-test was performed separately for each genotype. D1- $\mathrm{CB}^{-/-}$and WT mice showed higher interest for the tube containing the female, as described by the significant increase of time of investigation (WT: $t=3.782$; $p<0.01$; D1-CB1 $\left.{ }^{-1-}: t=3.489 ; p<0.01\right)$ and by number of interactions (WT: $t=3.904 ; p<0.01 ; \mathrm{D} 1-\mathrm{CB}^{-/-}: t=4.459 ; p<0.001$ ).

\section{Fear conditioning}

As shown in Figure 7A, unpaired $t$-test revealed that $\mathrm{D} 1-\mathrm{CB}^{-/-}$ showed a significant increase on freezing response to the tone at day $1(t=2.497 ; p<0.05)$ and to the context at day $2(t=3.210$; $p<0.01)$ as index of increased auditory-cued and contextual fear responses, respectively. When analyzed in 20-s intervals, all mice 

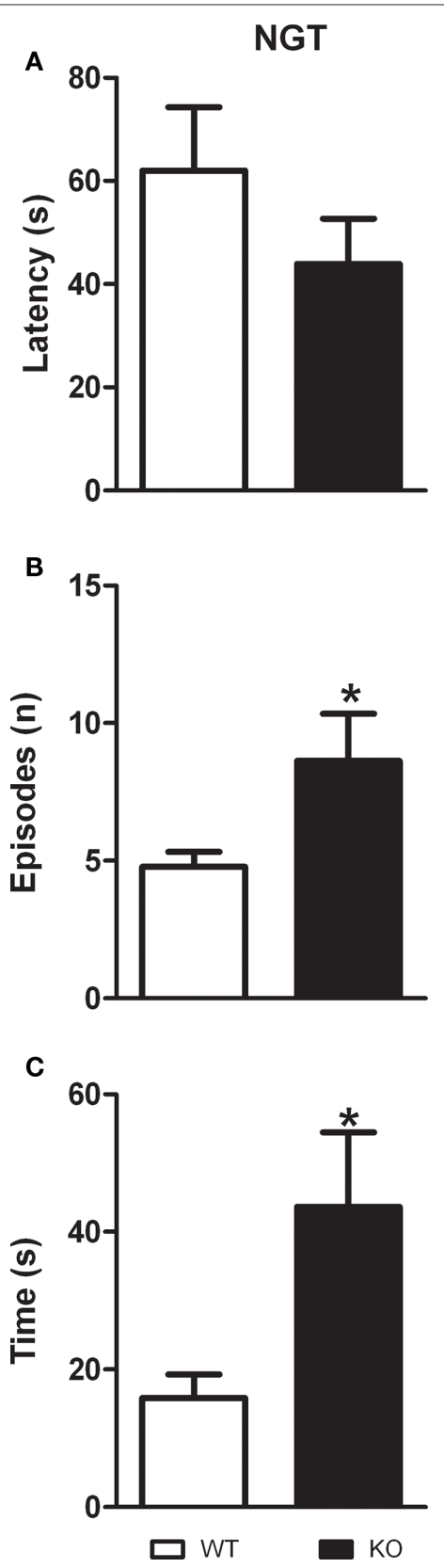

FIGURE 4 | Grooming behavior in D1-CB1-- mice. Conditional D1-CB1 ${ }^{-1-}$ mutant mice $(\mathrm{KO})$ and their respective wild-type $(\mathrm{WT})$ littermates were tested for the grooming activity measure. Data are presented as mean \pm SEM regarding latency to start grooming $(\mathbf{A})$, number of grooming episodes $(\mathbf{B})$ and total grooming duration (C). ${ }^{*} p<0.05$ as compared to WT mice (unpaired $t$-test).

showed the same initial freezing response on day 1 . However, whereas WT mice showed a rapidly waning freezing response during the tone presentation, $\mathrm{D} 1-\mathrm{CB}^{-/-}$mice showed a deficit in acute fear adaptation (Figure 6B). The second experiment, largely confirmed their phenotype (Figures 6C,D): D1-CB1 $1^{-/-}$ mice showed a significant increase on freezing response to the tone on day $1(t=4.234 ; p<0.001)$ and on day $7(t=2.923$; $p<0.01$, which again results from impaired acute fear adapta- tion over the course of tone presentation (Figure 6D). Freezing before tone presentation on day 1 was low and indistinguishable between the two groups.

\section{DISCUSSION}

In the present study we provide first evidence that the genetic deletion of cannabinoids CB1Rs in dopamine D1Rs-expressing neurons is able to affect the emotional behavior in mice in highly selective manner. Several studies reported increased anxiety-related behaviors after impaired CB1R signaling only when aversive stimulus cannot be avoided (Haller et al., 2004, 2009; Thiemann et al., 2007; Kamprath et al., 2009). However, little is known about how ECS modulation of the DAergic system could be involved in this effect.

It is accepted that ECs modulate several neurotransmitter systems (glutamatergic, GABAergic, and DAergic) at multiple levels (Piomelli, 2003). In the brain, where exogenously administered ( $\Delta^{9}$-tetrahydrocannabinol $[\mathrm{THC}]$ ) and endogenously released cannabinoids exert most of their behavioral effects, the CB1Rs are expressed at different levels at different neuronal subpopulations. More specifically, they are present at very high levels in GABAergic interneurons, where they mediate cannabinoid-dependent inhibition of GABA release, and to a minor extent, in glutamatergic terminals (Marsicano and Lutz, 1999). In the glutamatergic neuronal subpopulation, they play a pivotal role in both neuroprotection and fear extinction in highly aversive situations, through the modulation of glutamate release, further confirming that the fear-alleviating effects of CB1 became evident primarily under highly aversive conditions (Monory et al., 2006; Kamprath et al., 2009; Moreira and Wotjak, 2010).

Several lines of evidence suggest that DA is released in several brain regions such as the amygdala and prefrontal cortex under stress conditions. By acting on D1- or D2-like receptors, DA is involved in physiological processes subserving affective behaviors and emotional learning (LeDoux, 2000). Although, coexpression of the cannabinoid CB1Rs and D1Rs supports an ECS-DAergic system cross-talk, as in forebrain basal ganglia and piriform cortex, the exact role of D1Rs is not fully understood. Thus, the development of conditional CB1 mutant mice, in which the CB1Rs are specifically deleted in neurons expressing D1Rs (Monory et al., 2007) has been an useful tool to understand their role in the emotional behavior.

It should be recalled that growing evidence indicates that measures of anxiety from different tests could reflect different states of anxiety. This prompted us to use different behavioral paradigms such as exploration-based tests and social paradigms, that primarily focus on reciprocal SI and on the preference for social novelty, respectively, as well as tasks involving a strong mnemonic component, such as fear based tests, to assess different aspects that could mimic symptoms of human anxiety disorders as agoraphobia, social phobia or post traumatic stress disorder (Lister, 1990; File, 1992; Cryan and Holmes, 2005).

The first novel result of the present study was that $\mathrm{D} 1-\mathrm{CB} 1^{-/-}$mice did not show any anxiety-like phenotype when tested in exploratory behavioral paradigms such as EPM, LD, or NOI. These procedures mostly reflect the conflict between exploration and avoidance of a novel environment; thus, the inhibition of exploratory behavior given by the reduced open arms or light compartment entries and novel object exploration is commonly associated with high emotionality or anxiety. D1- $\mathrm{CB}^{-/-}$mice also failed to show alteration in spontaneous 

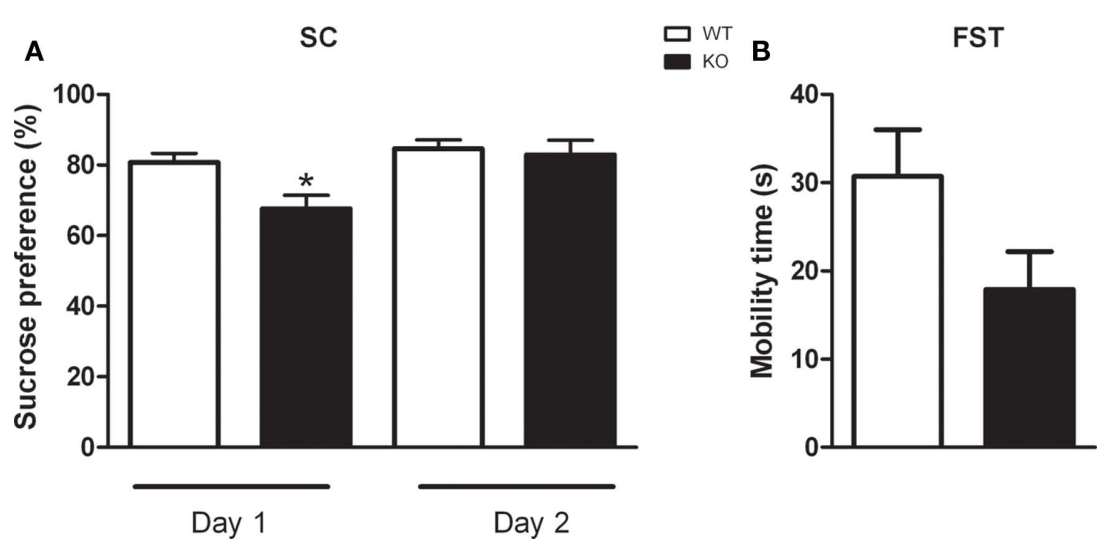

FIGURE 5 | Depressive-like behaviors of D1-CB1-r-mice. Conditional D1-CB1 $1^{-1-}$ mutant mice (KO) and their respective wild-type (WT) littermates were tested in the sucrose consumption test $(\mathbf{A})$ or in the forced swim test
(FST) paradigm (B). Data are presented as mean \pm SEM regarding percentage of sucrose consumption or mobility time expressed in seconds. ${ }^{*} p<0.05$ as compared to WT mice (unpaired $t$-test).

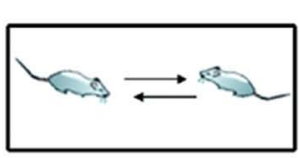

SI

A

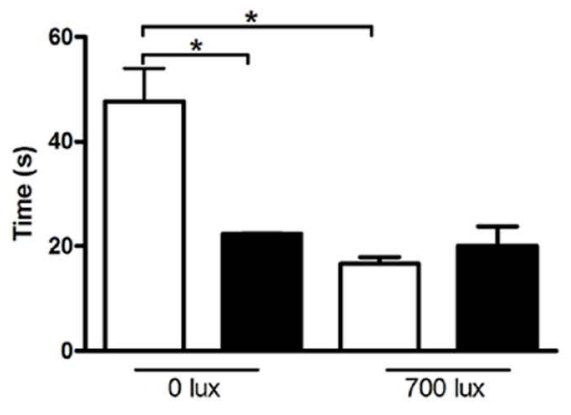

B

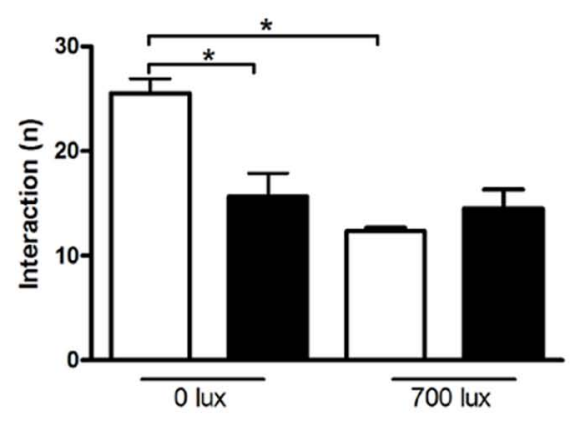

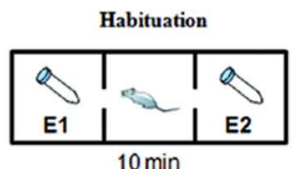

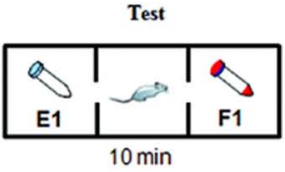

$\operatorname{Sin} v$

C

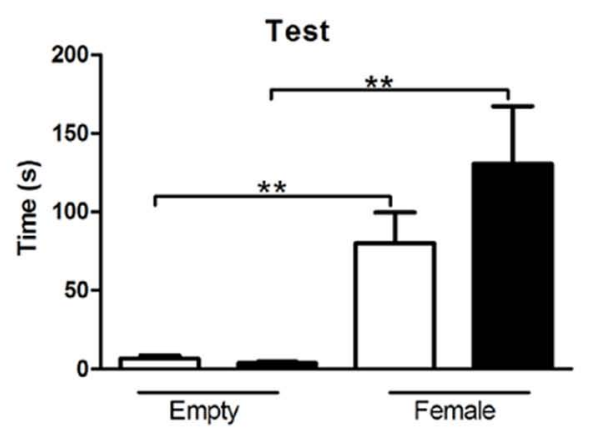

D

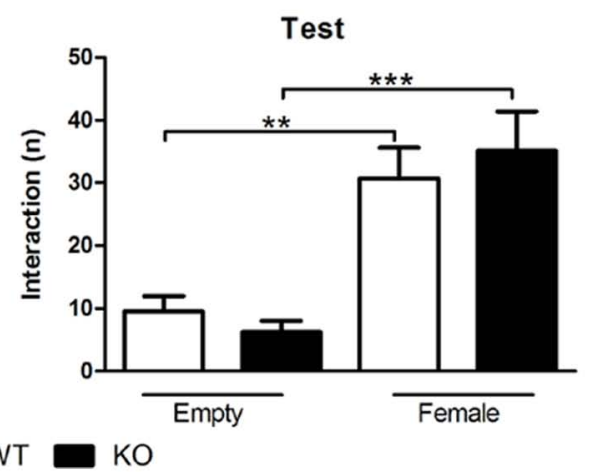

FIGURE 6 | Social behaviors in D1-CB1--- mice. Conditional D1-CB1-- mutant mice $(K O)$ and their respective wild-type (WT) littermates were tested in the social interaction $(\mathbf{A}, \mathbf{B})$ or in the social investigation $\mathbf{( C , D )}$ test. Data are presented as mean \pm SEM regarding time in interaction and number of interactions. E1: empty tube 1; E2: empty tube 2; F1: tube with female. ${ }^{*} p<0.05,{ }^{*} p<0.01,{ }^{*}{ }^{*} p<0.01$ (Newman-Keuls post hoc test or unpaired t-test). 

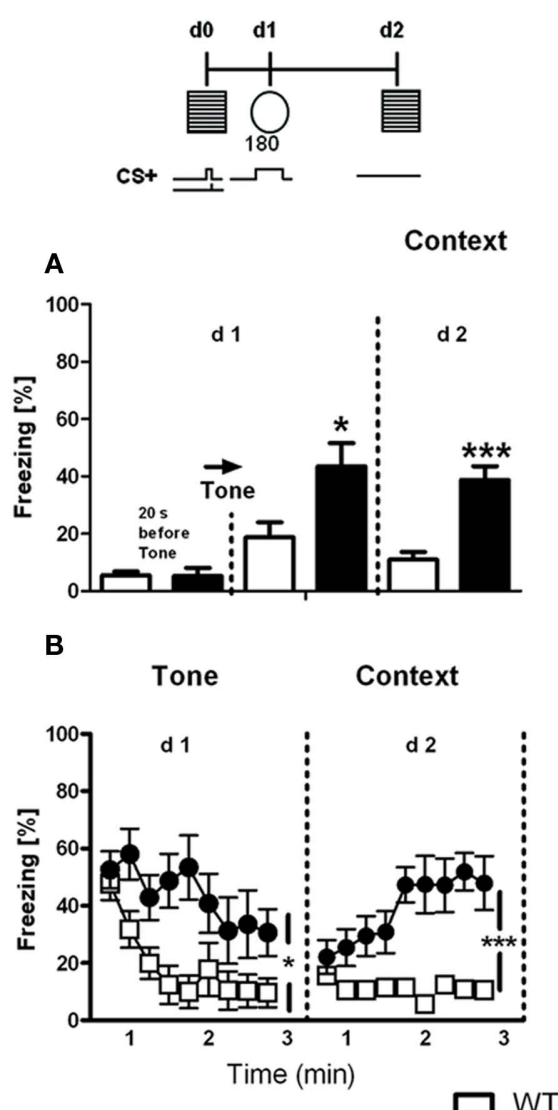

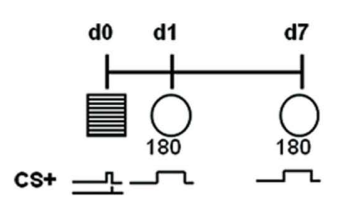

C Tone

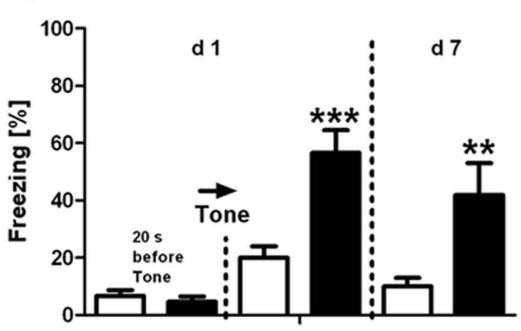

D

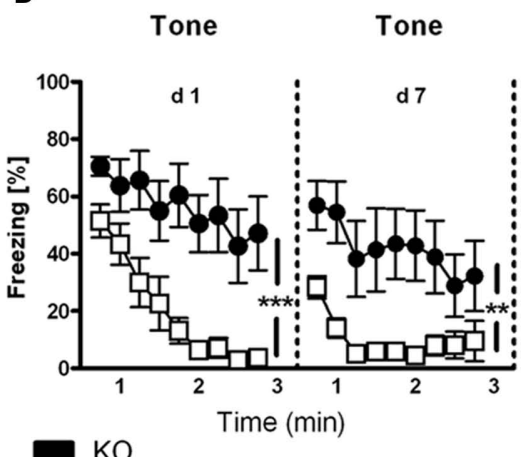

FIGURE 7 | Fear memory in D1-CB1-1- mice. Auditory-cued (Tone) and contextual (Context) fear memory assessed by freezing responses (mean \pm SEM) of conditional D1-CB1-- mutant mice $(\mathrm{KO})$ and their respective wild-type (WT) littermates in two independent sets of experiments (A/B, C/D). If not stated otherwise, freezing was averaged over the entire $180 \mathrm{~s}$ observation periods $(\mathbf{A}, \mathbf{C})$ or analyzed in $20 \mathrm{~s}$ intervals (B,D). ${ }^{*} p<0.05,{ }^{* *} p<0.01,{ }^{* * *} p<0.001$ as compared to WT mice (unpaired $t$-test). exploration and locomotor behavior. These findings are in line with previous data showing no anxiety-like phenotype in mice with total CB1Rs deletion and with specific CB1Rs deletion on glutamatergic neurons (Marsicano et al., 2002; Jacob et al., 2009). However, the D1$\mathrm{CB}^{-1-}$ mice showed increased grooming activity. Grooming is considered a "maintenance" behavior, a common species-characteristic movement pattern with readily definable components (Bolles, 1960) that serves a range of adaptive functions, including stress reduction and social interplay (Kalueff and Tuohimaa, 2005). In rodents, spontaneous grooming behavior may occupy as much as $25-40 \%$ of the wakeful time, but it is specifically elicited in situations (i.e., NGT) in which an animal is in stress-induced conflict or frustration, as well as being reduced following anxiolytic treatment (Dunn et al., 1981; Gispen and Isaacson, 1981; van Erp et al., 1994; Micale et al., 2008). Thus, our results suggest that if the exposure to novelty cannot be controlled by the animals, the novel environment is able to influence the emotionality of $\mathrm{D} 1-\mathrm{CB} 1^{-1-}$ mice.

The D1-CB1 ${ }^{-/-}$mice exhibited a decreased preference for sweet solutions on the first but not on the second day of the SC test under basal conditions, indicating a mild anhedonia-like state. Although anhedonia is commonly associated with depression-like behavior phenotype, mutant mice performed normally in the FST, a pro- cedure widely used for evaluating behavioral despair in rodents (Cryan and Holmes, 2005). Thus, the modulation of depressivelike behaviors in $\mathrm{D} 1-\mathrm{CB}^{-1-}$ mice evaluated in different tasks may be mediated by distinct neuronal circuits. On the other hand, the lower SC was only evident upon the first confrontation with the novel taste (day 1) and disappeared on the next day, suggesting a significant contribution of neophobia. In fact, a weak- to moderate anxiety-like phenotype of $\mathrm{D} 1-\mathrm{CB1}^{-/-}$mice became evident when the animals were tested under low (0 lux) aversive conditions in an unavoidable situation (i.e. SI test), where the WT control mice demonstrated social approach (intense interaction). These findings suggest that the deletion of CB1Rs specifically in D1Rs-expressing neurons elicited SI impairments, similarly to those observed in mice lacking CB1 in cortical glutamatergic neurons (Jacob et al., 2009). By contrast, it did not affect the preference for social novelty with female stimulus.

Interestingly, D1-CB1 $1^{-/-}$mice showed sustained auditory-cued and contextual fear responses, thus resembling the phenotype of impaired fear adaptation observed in mice with complete deletion of CB1Rs (Marsicano et al., 2002; Kamprath et al., 2006) or selective deletion from principal neurons of the forebrain (Kamprath et al., 2009). Since Monory et al. (2007) showed that the deletion of 
$\mathrm{CB} 1$ in dopamine D1-expressing neurons did not alter the analgesic effects of THC, we can exclude the possibility that the phenotype of $\mathrm{D} 1-\mathrm{CB}^{-/-}$mice in the FC paradigms could be due to different nociceptive thresholds.

Currently, we do not know exactly how the CB1Rs modulate D1Rs-mediated emotional behavior. However, due to their coexpression, it is tempting to assume that a direct or indirect receptor-receptor interaction, via intracellular signaling pathways, might be involved (Glass et al., 1997; Gangarossa et al., 2011). In support of this hypothesis, Martín et al. (2008) showed in rats that pharmacological CB1R blockade or activation could facilitate or inhibit animal behavior, respectively; and this latter effect was absent in D1Rs knock-out mice, demonstrating a DR1s dependence on CB1-mediated actions. Thus, in the highly aversive situations of FC paradigms, where a strong stimulus as a footshock was delivered, the EC signaling failed. This happens due to the CB1 deletion, to negatively modulate the D1Rs-emotional behavior,

\section{REFERENCES}

Bernabeu, R., Bevilaqua, L., Ardenghi, P., Bromberg, E., Schmitz, P., Bianchin, M., Izquierdo, I., and Medina, J. H. (1997). Involvement of hippocampal cAMP/cAMP-dependent protein kinase signaling pathways in a late memory consolidation phase of aversively motivated learning in rats. Proc. Natl. Acad. Sci. U.S.A. 94, 7041-7046.

Bolles, R. C. (1960). Grooming behavior in the rat. J. Comp. Physiol. Psychol.53, 306-310.

Crawley, J. N., Chen, T., Puri, A., Washburn, R., Sullivan, T. L., Hill, J. M., Young, N. B., Nadler, J. J., Moy, S. S., Young, L. J., Caldwell, H. K., and Young, W. S. (2007). Social approach behaviors in oxytocin knockout mice: comparison of two independent lines tested in different laboratory environments. Neuropeptides 41, 145-163.

Cryan, J. F., and Holmes, A. (2005). The ascent of mouse: advances in modeling human depression and anxiety. Nat. Rev. Drug Discov. 4, 775-790.

Di Marzo, V. (2008). Targeting the endocannabinoid system: to enhance or reduce? Nat. Rev. Drug Discov. 7, 438-455.

Dunn, A. J., Guild, A. L., Kramarcy, N. R., and Ware, M. D. (1981). Benzodiazepines decrease grooming in response to novelty but not ACTH or beta-endorphin. Pharmacol. Biochem. Behav. 15, 605-608.

El-Ghundi, M., O’Dowd, B. F., and George, S. R. (2001). Prolonged fear responses in mice lacking dopamine D1 receptor. Brain Res. 892, 86-93.

File, S. E. (1992). Usefulness of animal models with newer anxiolytics. Clin. Neuropharmacol. 15, 525A-526A.

Gangarossa, G., Di Benedetto, M., O’Sullivan, G. J., Dunleavy, M., Alcacer,
C., Bonito-Oliva, A., Henshall, D. C., Waddington, J. L., Valjent, E., and Fisone, G. (2011). Convulsant doses of in Erk-dependent increases in Zif268 and Arc/Arg3.1 expression in mouse dentate gyrus. PLoS ONE 6, e19415. doi: 10.1371/journal.pone.0019415 ACTH-induced excessive grooming in the rat. Pharmacol. Ther.12, 209-246.

Glass, M., Brodie, J. M., and Maneuf, Y. P. (1997). Modulation of neurotransmission by cannabinoids in the basal ganglia. Eur. J. Neurosci. 9, 199-203.

Haller, J., Barna, I., Barsvari, B., Gyimesi Pelczer, K., Yasar, S., Panlilio, L. V., and Goldberg, S. (2009). Interactions between environmental aversiveness and the anxiolytic effects of enhanced cannabinoid signaling by FAAH inhibition in rats. Psychopharmacology (Berl.) 204, 607-616.

Haller, J., Varga, B., Ledent, C., Barna, I., and Freund, T. F. (2004). Contextdependent effects of CB1 cannabinoid gene disruption on anxiety-like and social behaviour in mice. Eur. J. Neurosci. 19, 1906-1912.

Hermann, H., Marsicano, G., and Lutz, B. (2002). Coexpression of the cannabinoid receptor type 1 with dopamine and serotonin receptors in distinct neuronal subpopulations of the adult mouse forebrain. Neuroscience 109, 451-460.

Jacob, W., Yassouridis, A., Marsicano, G., Monory, K., Lutz, B., and Wotjak, C. T. (2009). Endocannabinoids render exploratory behaviour largely independent of the test aversiveness: role of glutamatergic transmission. Genes Brain Behav. 8, 685-698.

Kalueff, A. V., and Tuohimaa, P. (2005). Contrasting grooming phenotypes in three mouse strains markedly different a dopamine D1 receptor agonist result

Gispen, W. H., and Isaacson, R. L. (1981).

leading to an impaired fear adaptation. However, we cannot rule out the involvement of different pathways as well as the potential compensatory mechanisms occurring during development, which represents a limitation of experiments with mutant mice in general. Nevertheless, the present data add a new facet to the cross-talk between DAergic and the EC systems, within the framework of fear adaptation.

\section{ACKNOWLEDGMENTS}

We thank Giovanni Marsicano (INSERM, Bordeaux, France) and Beat Lutz (University of Mainz, Germany) for sharing the D1-CB1 ${ }^{-1-}$ with us and the Deutsch-Französische Hochschule for continuous support (CB1_G2R-FA-151). We also thank Caitlin Riebe for her comments on the manuscript. Ana Luisa Terzian is supported by CNPq (process 290008/2009-3). Vincenzo Micale is supported by ECNP Research Grant for Young Scientists 2010.

in anxiety and activity (129S1, BALB/c and NMRI). Behav. Brain Res. 160 $1-10$.

Kamei,H., Kameyama, T., and Nabeshima, T. (1995). Activation of both dopamine D1 and D2 receptors necessary for amelioration of conditioned fear stress. Eur. J. Pharmacol. 273, 229-233.

Kamprath, K., Marsicano, G., Tang, J., Monory, K., Bisogno, T., Di Marzo, V., Lutz, B., and Wotjak, C. T. (2006). Cannabinoid CB1 receptor mediates fear extinction via habituation-like processes. J. Neurosci. 26, 6677-6686.

Kamprath, K., Plendl, W., Marsicano, G., Deussing, J. M., Wurst, W., Lutz, B., and Wotjak, C. T. (2009). Endocannabinoids mediate acute fear adaptation via glutamatergic neurons independently of corticotropin-releasing hormone signaling. Genes Brain Behav. 8, 203-211.

Kamprath, K., and Wotjak, C. T. (2004). Nonassociative learning processes determine expression and extinction of conditioned fear in mice. Learn. Mem. 11, 770-786.

Laviolette, S. R., and Grace, A. A. (2006). The roles of cannabinoid and dopamine receptor systems in neural emotional learning circuits: implications for schizophrenia and addiction. Cell. Mol. Life Sci. 63, 1597-1613.

LeDoux, J. E. (2000). Emotion circuits in the brain. Annu. Rev. Neurosci. 23, 155-184.

Lister, R. G. (1990). Ethologically-based animal models of anxiety disorders. Pharmacol. Ther. 46, 321-340.

Marsicano, G., and Lutz, B. (1999). Expression of the cannabinoid receptor $\mathrm{CB} 1$ in distinct neuronal subpopulations in the adult mouse forebrain. Eur. J. Neurosci. 11, 4213-4225.

Marsicano, G., Wotjak, C. T., Azad, S. C., Bisogno, T., Rammes, G., Cascio, M.
G., Hermann, H., Tang, J., Hofmann, C., Zieglgänsberger, W., Di Marzo, V., and Lutz, B. (2002). The endogenous cannabinoid system controls extinction of aversive memories. Nature 418, 530-534.

Martín, A. B., Fernandez-Espejo, E., Ferrer, B., Gorriti, M. A., Bilbao, A., Navarro, M., Rodriguez de Fonseca, F., and Moratalla, R. (2008). Expression and function of $\mathrm{CB} 1$ receptor in the rat striatum: localization and effects on D1 and D2 dopamine receptor-mediated motor behaviors. Neuropsychopharmacology 33, 1667-1679.

Micale, V., Tamburella, A., Leggio, G. M., Mazzola, C., Li Volsi, V., and Drago, F. (2008). Behavioral effects of saredutant, a tachykinin NK2 receptor antagonist, in experimental models of mood disorders under basal and stress-related conditions. Pharmacol. Biochem. Behav. 90, 463-469.

Monory, K., Blaudzun, H., Massa, F., Kaiser, N., Lemberger, T., Schütz, G., Wotjak, C. T., Lutz, B., and Marsicano, G. (2007). Genetic dissection of behavioural and autonomic effects of delta (9)-tetrahydrocannabinol in mice. PLoS Biol. 5, e269. doi: 10.1371/journal.pbio.0050269

Monory, K., Massa, F., Egertová, M., Eder, M., Blaudzun, H., Westenbroek, R., Kelsch, W., Jacob, W., Marsch, R., Ekker, M., Long, J., Rubenstein, J. L., Goebbels, S., Nave, K. A., During, M., Klugmann, M., Wölfel, B., Dodt, H. U., Zieglgänsberger, W., Wotjak, C. T., Mackie, K., Elphick, M. R., Marsicano, G., and Lutz, B. (2006). The endocannabinoid system controls key epileptogenic circuits in the hippocampus. Neuron 51, 455-466.

Moreira, F. A., and Wotjak, C. T. (2010). Cannabinoids and anxiety. Curr. Top. Behav. Neurosci. 2, 429-450. 
Nagai, T., Takuma, K., Kamei, H., Ito, Y., Nakamichi, N., Ibi, D., Nakanishi, Y., Murai, M., Mizoguchi, H., Nabeshima, T., and Yamada, K. (2007). Dopamine D1 receptors regulate protein synthesis-dependent long-term recognition memory via extracellular signalregulated kinase $1 / 2$ in the prefrontal cortex. Learn. Mem. 14, 117-125.

Pamplona,F.A.,Henes, K., Micale, V.,Mauch, C. P., Takahashi, R. N., and Wotjak, C. T. (2011). Prolonged fear incubation leads to generalized avoidance behavior in mice. J. Psychiatr. Res. 45, 354-360.

Pellow, S., Chopin, P., and File, S. E. (1985). Are the anxiogenic effects of yohimbine mediated by its action at benzodiazepine receptors? Neurosci. Lett. 55, 5-9.

Piomelli, D. (2003). The molecular logic of endocannabinoid signalling. Nat. Rev. Neurosci. 4, 873-884.

Plendl, W., and Wotjak, C. T. (2010). Dissociation of within- and between-session extinction of conditioned fear. J. Neurosci. 30, 4990-4998. Porsolt, R. D., Bertin, A., and Jalfre, M. (1978). "Behavioural despair" in rats and mice: strain differences and the effects of imipramine. Eur. J. Pharmacol. 51, 291-294.

Smit-Rigter, L. A, Wadman, W. J., and van Hooft, J. A. (2010). Impaired social behavior in 5-HT(3A) receptor knockout mice. Front. Behav. Neurosci. 4:169. doi: 10.3389/ fnbeh.2010.00169

Strekalova, T., and Steinbusch, H. W. (2010). Measuring behavior in mice with chronic stress depression paradigm. Prog. Neuropsychopharmacol. Biol. Psychiatry 34, 348-361.

Thiemann, G., Fletcher, B. C., Ledent, C., Molleman, A., and Hasenöhrl, R. U. (2007). The genetic versus pharmacological invalidation of the cannabinoid $\mathrm{CB}(1)$ receptor results in differential effects on "non-associative" memory and forebrain monoamine concentrations in mice. Neurobiol. Learn. Mem. 88, 416-423.

van Erp, A. M., Kruk, M. R., Meelis, W., and Willekens-Bramer, D. C. (1994). Effect of environmental stressors on time course, variability and form of self-grooming in the rat: handling, social contact, defeat, novelty, restraint, and fur moistening. Behav. Brain Res. 65, 47-55.

Zenko, M., Zhu, Y., Dremencov, E., Ren, W., Xu, L., and Zhang, X. (2011). Requirement for the endocannabinoid system in social interaction impairment induced by coactivation of dopamine D1 and D2 receptors in the piriform cortex. J. Neurosci. Res.89, 1245-1258.

Conflict of Interest Statement: The authors declare that the research was conducted in the absence of any commercial or financial relationships that could be construed as a potential conflict of interest.

Received: 08 June 2011; paper pending published: 20 June 2011; accepted: 01 August 2011; published online: 17 August 2011.

Citation: Terzian AL, Drago F, Wotjak CT and Micale V (2011) The dopamine and cannabinoid interaction in the modulation of emotions and cognition: assessing the role of cannabinoid $C B 1$ receptor in neurons expressing dopamine D1 receptors. Front. Behav. Neurosci. 5:49. doi: 10.3389/ fnbeh.2011.00049

Copyright @ 2011 Terzian, Drago, Wotjak and Micale. This is an open-access article subject to a non-exclusive license between the authors and Frontiers Media $S A$, which permits use, distribution and reproduction in other forums, provided the original authors and source are credited and other Frontiers conditions are complied with. 